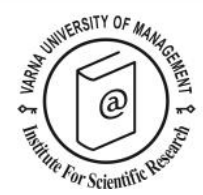

\title{
McKercher, B. and Prideaux, B. (2020). Tourism Theories, Concepts and Models. ISBN: 9781911635352, Oxford, UK: Goodfellow Publishers Ltd. 256 pp.
}

\author{
Reviewed by \\ Rodolfo Baggio ${ }^{1 *}$
}

\begin{abstract}
${ }^{1}$ Master in Economics and Tourism and Dondena Center for Research on Social Dynamics and Public Policy, Bocconi University, Milan, Italy; Division for Social Sciences and Humanities, School of Core Engineering Education, Tomsk Polytechnic University, Tomsk, Russia. Email: rodolfo.baggio@unibocconi.it
\end{abstract}

${ }^{*}$ Corresponding author

Citation: Baggio, R. (2022). Book review of McKercher, B. and Prideaux, B. (2020). Tourism Theories, Concepts and Models. ISBN: 9781911635352, Oxford, UK: Goodfellow Publishers Ltd. European Journal of Tourism Research 30, 3021. 
The authors lead the reader through a long and fascinating journey through a much-debated issue, that of the theoretical foundations of a complex and complicated domain: tourism. A discussion that seems to go on since academics and researchers have put together a "critical mass" of investigations and reflections of the many facets of this phenomenon and its basic constituents.

As we all know tourism is an intriguing subject of study, probably because no accepted definition of the matter exists. It involves many areas of study, research methodologies, and applications, has fairly indefinite boundaries and brings together quite many different activities, with a wide variety of products and services that use different technologies for the production process. It exhibits so little homogeneity, that it may be even questioned whether it can be classified as an industry by itself in the traditional sense.

What the vast literature has produced so far can be summarized in the fifty themes that the authors list at the end of the book and that are described and discussed throughout the book. If we map their connections (see figure 1) it is immediately clear (p. 306) "what a multi-discipline tourism is and why it is such a fascinating field to examine" and "also highlights the innate challenges we face when trying to teach it in a simplistic manner, for it is impossible to understand tourism with having at least a basic knowledge of the many area, fields and disciplines that have contributed to our collective knowledge, and how they interact". Quite a dense and intricate set of relationships.

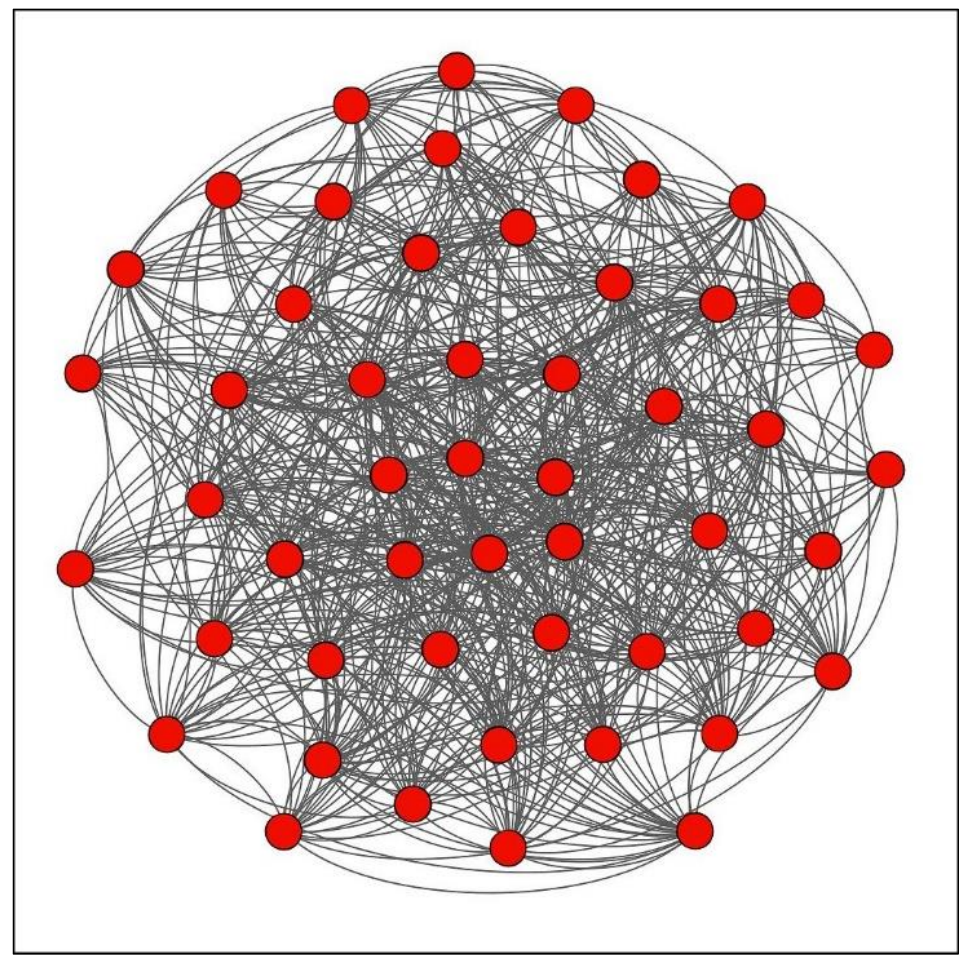

Figure 1. The relationships between the themes of the book

The main objective of the book, as the title says, is that of providing, or at least attempting at providing, a summary of the theories and models that emerge from the vast literature on the subject. This is a 
much-needed task. Although usually interpreted as an applied field of research, there is no doubt that without a good theoretical foundation (or set of foundations) no real sound applications can be imagined.

The history of science is full of examples in this regard. No mobile phones would be possible without Maxwell's electromagnetic theory, and our GPS system would not work without Einstein's theory of relativity, without quantum mechanics there would be no microchips or lasers, and the list can go on almost indefinitely. As well stated by Garrison (2000: 3): "Theoretical inquiry is central to the vitality and development of a field of practice - not to mention its recognition and credibility from those not yet initiated into the field. The theoretical foundations of a field describe and inform the practice and provide the primary means to guide future developments". Just what tourism needs.

The idea of tourism research as mainly 'applied' is well known to all of us and made explicit by the insistent requests, to any of our contributions to the literature, to provide "implications" of what we propose. On the other hand, the call for a theoretical framing of our work is something mainly editors strongly look after, keeping insisting that we provide novel "contributions" to the theory. Even if this risks generating a paradoxical trap, since a really strong provision of this kind does not necessarily have an immediate application. And of this fact too the history of science is full (see for example those mentioned above), since none of those theorists had, at their time, any idea, or even cared, about possible practical applications. Unless by "theory" our reviewers and editors mean something different from what is usually meant.

Be as it is, this book is a powerful help for clarifying this and other issues in the realm of the theoretical discourse on the many matters involving tourism. This is exactly the objective of the first part of the book, titled Setting the Stage. In this section, the treatment contains some basic definitions and a discussion aimed at understanding what a theory is, what a good or a bad theory is, and what difference exists between theories, concepts, and models. The part also describes and discusses several different varieties of theory used in tourism.

The other four parts of the book set to analyze the issue from different perspectives, always from a theoretical viewpoint. Part 2 deals with the supply side of tourism and examines the basic workings of the area. Attractions, spatial interactions, and large scale movements of tourists together with the political economy related to the field and the fundamental activities of forecasting in their different approaches are treated mostly based, even if not always made explicit, on the long and relevant experience of the authors.

Being a highly dynamic environment, tourism has seen, and still has, an evolution that affects all of its components. Therefore, quite logically, Part 3 is dedicated to the analysis of the main ideas on what this evolution is and what this evolution consists of. Here two main lines of thoughts are discussed. One is that of Butler, which roots the evolutionary developments in the supply-side perspective, showing the progression of the different phases and using the idea of carrying capacity as an indicator for measuring the development. The second is the one of Plog that bases the progression on the capacity to attract progressively different sorts of tourist, and that focuses on the necessity of careful management to avoid the risk of becoming the origin of own disruption. Both are complementary and have received a lot of attention in the past. However, they reflect a relatively "old" idea of almost linear (or linearizable) dynamics that has been recognized relatively recently also in tourism as not fully suitable to explain the many facets of the phenomenon. Therefore, the last chapter of this part deals with a more modern 
approach: that of the science of complexity which has proved to be more appropriate in dealing with the dynamic behaviour of the systems at the basis of the phenomenon.

The next section (Part 4) deals with the other side of the Moon: the tourists, without whom, as we sadly experience in the actual difficult times, all other considerations seem meaningless. Here the focus is on the social and anthropological aspects and on what are the numerous motivations that push people to move to other places.

The final part of the book is dedicated to the impacts tourism has and to the hot topic of sustainability. Here too the authors, although discussing well the issues related to climate and climate change, do not limit the treatment to these topics, as too many do, but take into consideration also the problems related to a possible economic and social sustainability. With this spectrum, they then discuss the challenges and the contradictions that putting together all these issues may raise and conclude reviewing a number of possible models that can help in devising realistic strategies for addressing the sustainability issues.

Finally, one very welcome characteristic is that this is a "book" and not a collection of different contributions. Edited works could be interesting and, in some way, useful, but they too often lack coherence and uniformity in the treatment of a subject. Thing that this work does in a quite worthy manner.

Written in a highly readable language, within the reach of most students and scholars of tourism, the book will surely become a standard reference for all serious researchers of tourism matters. It also constitutes an important starting point for a deeper work aimed at consolidating the different approaches and producing a reduced set of higher-level and comprehensive frameworks that the tourism domain needs.

\section{References}

Garrison, R. (2000). Theoretical Challenges for Distance Education in the 21st Century: A Shift from Structural to Transactional Issues. International Review of Research in Open and Distance Learning, 1(1). https://doi.org/10.19173/irrodl.vii1.2

Received: 15/04/2021

Accepted: 19/04/2021

Coordinating editor: Stanislav Ivanov 